\title{
Observation of preparation and administration of drugs by nursing assistants in patients with enteral feeding tube
}

\author{
Joana Heydrich, Isabela Heineck, Denise Bueno \\ Department of Drugs Production and Control, School of Pharmacy, Federal University of Rio Grande do Sul
}

\begin{abstract}
This study aimed to know the standard of preparation and administration of medicines to patients using probes of enteral nutrition (SNE) hospitalized in a university hospital in Porto Alegre. Were accompanied sixty nursing auxiliaries, in two units of hospital, in their routine work and observed their techniques. The practice was compared with procedures that are part of the rules for administration of medicines to patients on enteral therapy. The auxiliary held a grinding in $90 \%$ of cases of solid pharmaceutical preparation. For this procedure they used preferably the mortar and pistil (63.3\%). The dilution of the drugs was made mainly with tap water $(78.3 \%)$. Most professionals $(91.1 \%)$ prepare and administer together all medications that were prescribed to the patient. Only four assistants performed the procedure separately. The washing of the SNE after administration of drugs was made for $75 \%$ of assistants. It was observed a great diversity of working methods used at the derivation, dilution and administration of medicines by nursing auxiliaries.
\end{abstract}

Uniterms: Enteral nutrition. Drugs / administration. Nursing / practice.

Este estudo objetivou conhecer o padrão de preparo e administração de medicamentos a pacientes em uso de sondas de nutrição enteral (SNE) internados em hospital universitário de Porto Alegre. Foram acompanhados sessenta auxiliares de enfermagem, em duas unidades de internação, em suas rotinas de trabalho e observadas as suas técnicas, estas foram comparadas com os procedimentos que fazem parte das normas de administração de medicamentos a pacientes em terapia enteral. Os auxiliares realizavam a trituração em $90 \%$ dos casos de derivação de forma farmacêutica sólida e para este procedimento, utilizavam preferencialmente os materiais almofariz e pistilo (63,3\%). A diluição dos medicamentos era feita principalmente com água da torneira $(78,3 \%)$. A maioria dos profissionais $(91,1 \%)$ preparava e administrava juntamente todos os medicamentos que eram prescritos ao paciente. Somente quatro auxiliares realizaram o procedimento em separado. A lavagem da SNE após a administração dos medicamentos foi feita por $75 \%$ dos auxiliares. Constatou-se grande diversidade de métodos de trabalho utilizados no momento da derivação, diluição e administração dos medicamentos pelos auxiliares de enfermagem.

Unitermos: Nutrição enteral. Medicamentos/administração. Enfermagem/práticas.

\section{INTRODUCTION}

Enteral nutrition refers to the provision of nutrients to gastrointestinal tract through a tube or catheter, when the quantity of oral ingestion is inadequate (Linjakumpu et al., 2002). It is known as a very safe and satisfactory manner to provide nutrition to patients with partially or completely

\footnotetext{
*Correspondence: D. Bueno. Departamento de Produção e Controle de Medicamentos, Faculdade de Farmácia, Universidade Federal do Rio Grande do Sul, Av.Ipiranga, 2752 - 90610-000 - Porto Alegre - RS, Brasil. E-mail: denise. bueno@ufrgs.br
}

affected capacity of oral ingestion. When patients utilizing enteral feeding tubes do not present effective deglutition and are under risk of pulmonary aspiration, feeding tubes are also utilized for drug administration, which is a routine procedure in hospital practice (Belknap, Seifert, Petermann, 1997).

The drug administration via enteral catheters requires liquid pharmaceutical forms; however, the unavailability of liquid pharmaceutical forms leads to derivation of solid pharmaceutical forms. Drug degradation and alteration of bioavailability, with degraded therapy effi- 
cacy, are some of the potential problems that occur in the transformation of solid pharmaceutical forms (Viguria et $a l ., 2001)$. The main problem reported regarding this type of drug administration is the obstruction of enteral feeding catheters. Even if the tubes are most times unclogged successfully, the occlusion removal requires additional time from nursing staff and delays the enteral nutrition (Belknap, Seifert, Petermann, 1997).

At hospitals, the number of patients requiring drug administration via enteral tube is high. The nursing team is primarily responsible for drug administration and tube care. Knowledge and techniques employed exert direct influence on the therapy results of these patients (Belknap, Seifert, Petermann, 1997).

Recommendations are easily found in literature (Gilbar, 1999; Seifert, Johnston, Rojas-Fernandez, 2002) for the preparation and administration of drugs to patients that receive enteral nutrition. The scientific community has also established similar norms for this type of drug administration to patients with EFC (Seifert, Johnston, Rojas-Fernandez, 2002).

The purpose of this study was to elaborate an observational study describing the drug preparation and administration forms to patients utilizing enteral tube, at admission units of a university hospital, and correlate the results obtained with the existing literature.

\section{METHODOLOGY}

The focus of this study was exploratory and descriptive. The investigation was performed from August to October 2004, at two admission units of a university hospital in the city of Porto Alegre-RS. The units selected for investigation were two: one with the highest number of patients with EFC, and another unit where patients had the highest number of drugs in solid form prescribed, according to a previous study (Heydrich, 2006).

The sample was comprised of $100 \%$ (60) nursing assistants from the two selected units, involving 15 from the morning shift, 18 from afternoon shift and 27 from night shift. The participant observation technique was utilized, observing the three work shifts of the hospital: morning, afternoon and night, from Monday to Friday, and the two shifts on Saturday and Sunday, for complete coverage and inspection of the routine of nursing assistants. During the six weeks of field observation, all assistants were observed, regardless the number of drug preparation procedures, as they all followed a shift elaborated for the observation of all assistants on different days, and at different times. A structured procedure was utilized and the results were organized and described in a field report.
The methodology was applied for the purposes of observing the existing practices for the preparation and administration of drugs to patients with EFC performed by nursing assistants at the units in question. There were no interventions in such practices during the study period.

The study was submitted and approved by the Research Ethics Committee of the HCPA.

\section{RESULTS}

Nursing assistants have been responsible for the preparation and administration of drugs to patients in enteral nutrition. The nursing professionals on weekdays are distributed into 6-hour day shifts and 12-hour night shift, and on weekends and holidays they follow 12-hour night and day shifts.

In the morning shift, 15 assistants were observed; in the afternoon shift, 18 assistants; in the night shift, 27 assistants, totaling 60 nursing assistants in different shifts and on different days.

These professionals were 25 to 56 years old, mean: 39 years old $(\mathrm{SD}=8)$. Women were predominant in the group, only 7 assistants were men.

The mean value of total time as nursing assistant was $14 \pm 8$ years, ranging from 1 to 29 years of profession. The mean value of total time as nursing assistant at the Hospital de Clínicas de Porto Alegre (HCPA) only was $8 \pm 7$ years of profession, including recently hired professionals to assistants for 29 years at the hospital. It should be noted that the HCPA is a university hospital with 750 admission beds.

Regarding their school level, 10 assistants had attended superior education course at a certain occasion in life and 6 were registered at a superior education course on the occasion of the study. Most of them (73\%) had completed the intermediate education level. Most of them $(82 \%)$ worked exclusively at the hospital.

For the derivation of the solid pharmaceutical form, $90 \%$ of the assistants performed trituration and the remaining assistants performed direct drug dilution for subsequent administration. Considering the assistants who performed trituration, $63.3 \%$ of them utilized "mortar and pistil", which are the adequate materials for this procedure. However, only pistil was also utilized or even only "mortar" and syringes for direct trituration in the blister of the solid pharmaceutical form. Drug preparations were also made in disposable plastic cups and directly in the syringe utilized for the administration in the tube. Sometimes, liquid drugs were diluted for subsequent administration.

The most frequent terms applied by nursing assistants and heard during the observation, at the moment of 
drug preparation, were "dissolve, dilute, melt and triturate". "Triturate" was the least frequent word, although it is the correct term. The utilization of adequate nomenclature is important for the professional, to understand the procedure being performed.

Of all assistants, 15 prepared and administered only one drug during the observed period, as only one drug was prescribed via tube to the patient. The other 45 assistants were taking care of patients with more prescribed drugs and only 4 of them prepared and administered each drug separately.

The preparation and administration of two drugs at the same time was the predominant scheme; in some cases, seven and eight drugs were prepared in the same container and administered.

Our investigators observed that the drugs were prepared first thing early in the morning and administered hours later.

Most nursing assistants stopped the enteral nutrition dripping at the moment of drug administration. None of them stopped feeding 30 minutes before and after the drug administration, as recommended in the literature.

Regarding the frequency of tube wash, $75 \%$ of the assistants washed the tube after the drug administration. Only three washed the tube before and after and 12 assistants did not wash the tube at any moment, before or after the drug administration.

\section{DISCUSSION}

Our study observed that the nursing assistants prepared and administered the drugs prescribed by the doctor to the patient, without any previous analysis of pharmaceutical form, drug dosage or interaction.

The mixture of drugs in pharmaceutical preparations is a known factor of potential drug interactions that can lead to tube obstruction and other problems.

No assistant added drugs directly to the enteral nutrition, a practice disapproved by several authors (Belknap, Seifert, Petermann, 1997; Cerulli, Malone, 1999; Engle, Hannawa, 1999; Thomson, Naysmith, Lindsay, 2000; Cornish, 2005). Considering the 60 assistants investigated at the two admission units, only one professional performed the work routine preparing and administering all drugs separately, washing the tube, diluting the derivation with distilled water and checking each drug prescribed to the patient at the moment of administration, according to the norms of drug administering to patients in enteral feeding therapy of the HCPA (Belknap, 1997).

The auscultation of air insufflation in the stomach before the drug administration is not part of the inter- national recommendations for drug administration, but this procedure can prevent future complications, such as pulmonary aspiration of enteral feeding, if the tube is misplaced or defective. One assistant in the study sample performed this procedure of checking the tube position.

The investigation on each nursing assistant enabled an understanding of individual and collective attitudes. Knowing the correct technique for drug administration to patients in nasal-enteral tube does not seem to interfere in the behavior of mixing drugs in the same preparation. Lack of time is the most frequent excuse to justify the procedure and their failure to read the established norms and attend trainings.

The practice of leaving tablets prepared hours before the administration moment was also verified. The work routine was not followed in an organized manner and each assistant performed his/her tasks following his/her own personal judgment.

Our study observed that $78.3 \%$ of the assistants utilized tap water for drug dilution. Tap water is not usually acceptable for the preparation of most aqueous pharmaceutical forms or for the preparation of prescriptions, due to chemical incompatibilities that can result from the combination of dissolved solids and drugs being added (Ansel, 2000).

In a study conducted by Belknap et al. (1997), in which a questionnaire was sent to the nurses of the American Association of Critical Care Nurses, $97 \%$ of the nurses reported that they knew the utilization of liquid forms of drugs reduces the prevalence of tube obstruction, but $54 \%$ of the drugs they administered had to be triturated. Over half of them administered enteric pills or extended release pills at least once on a typical day of the hospital, and $20 \%$ habitually administered them.

Seifert et al. (2002) conducted one study through questionnaires with nurses of Oklahoma, USA, to analyze the techniques of drug administration through EFC. The study reported that $16.7 \%$ and $9.7 \%$ of the nurses habitually triturated enteric coated and extended release pills, respectively.

\section{CONCLUSION}

This study enabled to observe the nursing assistants' conception of drugs administered to patients with EFC at the studied institution.

The study observed the need for developing, along with the nursing team, a protocol of drug administration to patients submitted to enteral therapy. This way, time factor related to the quality of work provided can be improved. These data show the differentiation between the practice 
recommended by specific literature for drugs administered through enteral feeding catheters and the usual clinical practice. The results obtained in this study support the need for training to this health practice.

\section{ACKNOWLEDGEMENTS}

To everyone from the Nursing Service and Pharmacy Service of the HCPA-Porto Alegre, who collaborated to the development of this study, and to FIPE.

\section{REFERENCES}

ANSEL, H. C.; POPOVICH, N. G.; ALLEN JUNIOR. L. V. Farmacotécnica: formas farmacêuticas \& sistemas de liberação de fármacos. 6. ed. São Paulo: Editorial Premier, p.288-291, 2000.

BELKNAP, D.C.; SEIFERT, C.F.; PETERMANN, M. Administration of medications through enteral feedings catheters. Am. J. Crit. Care, v.6, n.5, p.382-392, 1997.

CERULLI, J.; MALONE, M. Assessment of drug-related problems in clinical nutrition patients. J. Paren. Enteral Nutr., v.23, n.4, p.218-221, 1999.

CORNISH, P. "Avoid the crush": hazards of medication administration in patients with dysphagia or a feeding tube. Can. Med. Assoc. J., v.172, n.7, p.871-872, 2005.
ENGLE, K.K.; HANNAWA, T.E. Techniques for administering oral medications to critical care patients receiving continuous enteral nutrition. Am. J. Hosp. Pharm., v.56, n.14, p.1441-1444, 1999.

GILBAR, P.J. A guide to enteral drug administration in palliative care. Joint Program of Survey Methodology JPSM , v.17, n.3, p.197-207, 1999.

HEYDRICH, J. Padrão de utilização e administração de medicamentos em usuários de sonda de nutrição enteral internados em um hospital universitário. Porto Alegre, 2006. 114p. [Dissertação de Mestrado. Faculdade de Farmácia. Universidade Federal do Rio Grande do Sul].

LINJAKUMPU, T., HARTIKAINEN, S., KLAUKKA, T., VEIJOLA, J. Use of medications and polypharmacy are increasing among the elderly. J. Clin. Epidemiol., v.55, n.8, p.809-817, 2002.

SEIFERT, C.F.; JOHNSTON, B.A.; ROJAS-FERNANDEZ, C. Drug administration through enteral feeding catheters. Am. J. Hosp. Pharm., v.59, n.4, p.378-379, 2002.

THOMSON, F.C.; NAYSMITH, M.R.; LINDSAY, A. Managing drug therapy in patients receiving enteral and parenteral nutrition. Hosp. Pharm, v.7, n.6, p.155-164, 2000.

Recebido para publicação em 26 de março de 2008. Aceito para publicação em 01 de agosto de 2008. 